\title{
The South American K Index: Initial Steps from the Embrace Magnetometer Network
}

\author{
C. M. Denardini', M. Rockenbach ${ }^{2}$, M. A. Gende ${ }^{3}$, S. S. Chen ${ }^{1,4}$, P. R. Fagundes ${ }^{2}$, N. J. Schuch ${ }^{5}$, A. Petry ${ }^{5}$, \\ L. C. A. Resende ${ }^{1}$, J. Moro' \\ ${ }^{1}$ National Institute for Space Research (INPE), S. J. Campos-SP, Brazil \\ ${ }^{2}$ Instituto de Pesquisas e Desenvolvimento, Universidade do Vale do Paraíba (UNIVAP), S. J. Campos-SP, Brazil \\ ${ }^{3}$ Facultad de Ciencias Astronómicas y Geofísicas, Universidad Nacional de La Plata, La Plata - Buenos Aires, Argentina \\ ${ }^{4}$ Universidade de Taubaté (UNITAU), Taubaté-SP, Brazil \\ ${ }^{5}$ Southern Regional Space Research Center in collaboration with the LACESM/CT-UFSM, Santa Maria-RS, Brazil
}

Copyright 2013, SBGf - Sociedade Brasileira de Geofísica

This paper was prepared for presentation during the $13^{\text {th }}$ International Congress of the Brazilian Geophysical Society held in Rio de Janeiro, Brazil, August 26-29, 2013.

Contents of this paper were reviewed by the Technical Committee of the $13^{\text {th }}$ International Congress of the Brazilian Geophysical Society and do not necessarily International Congress of the Brazllian Geophysical Society and do not necessarily represent any position of the SBG, its officers or members. Electronic reproduction or of the Brazilian Geophysical Society is prohibited.

\section{Abstract}

In the present paper we present the first steps given towards the development of the South American K index (Ksa) based on the measurement made by the Embrace Magnetometer Network. We present: (a) a description of the magnetometer and of the network; (b) the procedure used to calibrate the network equipments; (c) the procedure to obtain each station $\mathrm{K}$ scale and its corresponding upper limits of ranges for the three-hour-range station $\mathrm{K}$ indices (thereafter referred as $\mathrm{K} 9$ threshold); and (d) some particularities regarding the Quiet Day Curve (QDC) deviation and its long term variation.

\section{Introduction}

Several studies based on magnetic data have being carried on since the early researches in the aeronomy field with the postulation of global ionospheric current sheets, nowadays known as the Solar Quiet (Sq) System, to explain the global variation in ground measurements of the Earth's magnetic field that is superimposed to the main fields (Chapman e Bartels, 1940; Vestine, 1960; Maeda e Kato, 1966; Lindzen e Chapman, 1969, Matsushita, 1969). Specifically with respect to low latitude aeronomy, Sugiura and Cain (1966) presented a model for the Equatorial Electrojet (EEJ) based on the horizontal magnetic component of the Earth's magnetic field $(\mathrm{H})$, measured with magnetometers. Most of their work was based in the previous works made by Maynard e Cahill Jr. (1965a,1965b). Also, comprehensive study on the geomagnetic aspects of the Counter-Electrojet (CEJ) was published by Mayaud (1977). Most of the data used was collected in several sectors, but in the Eastern South American sector. None of these kinds of studies mentioned above (or similar) was carried out in the Brazilian sector, which has a completely different magnetic configuration at the low latitudes, reaching -20 degrees of magnetic declination in some points. Therefore, one of the goals of the Embrace Magnetometer Network is to provide a database to cover most of this research area.

Another scientific goal intended to be covered by the measurements made with the Embrace Magnetometer
Network is to investigate the long term variation of the South American Magnetic Anomaly (SAMA) and the implication of its presence in the deviation of the magnetic indices used to monitor the Solar-Earth relationship associated with space weather, in a similar framework like the paper by Moro et al. (2012). With respect to magnetic data being used for deriving magnetic indices, several publications have been made (see, for instance, Bartels at al.,1939; Mayaud, 1968 ;Rostoker, 1972; and Takahashi et al., 2001, and references therein). Due to continental extension of the South American territory, we focus our attention the Kp index, which indicates geomagnetic disturbances in a simple manner and can be helpful for studying the dynamic relationship between the solar wind and the magnetosphere. It is given at 3-hour intervals and is derived from magnetic field data acquired at 11 ground stations distributed worldwide at sub-auroral latitudes $\left(49^{\circ}\right.$ $62^{\circ}$ ) has values ranging from 0 o to 9 o in 28 steps. Although the subscript ' $p$ ' intended to mean planetary (from the German word planetarische), the South American sector is poorly resented in Kp deviation. That was our motivation to start developing the South American K index (Ksa).

\section{Brief description of the magnetometer and the network}

The magnetometer chosen to operate in this network is a the three-axis fluxgate magnetometer built for compact and high performance precision measurements of the Earth's magnetic field vector with measuring total range of $\pm 70000 \mathrm{nT}$ and dynamic ranges of $\pm 250 \mathrm{nT}, \pm 1000 \mathrm{nT}$ and $\pm 2500 \mathrm{nT}$ covering the amplitude diurnal variations of the magnetic components from low to high latitude. It can be powered from either any $220 / 110$ VAC or \pm 12 VDC power supply, and the outputs are in the form of three analogue voltages from 0 to $\pm 2.5 \mathrm{VDC}$, proportional to the three magnetic vector components it is able to measure: the horizontal $(H)$, the declination (D), and the vertical (Z). Compact fluxgate sensors commercially available are assembled in PVC double wall cylindrical enclosures for high mechanical and thermal stability so that the magnetometer sensor is sealed in a $104-\mathrm{cm}$ long weatherproof cylinder having a diameter of $18 \mathrm{~cm}$. The data acquisition module rate is 20 bits and is set together with the electronic control unit and the USB data output. Data acquisition and monitoring software includes both local data storage and simultaneous upload to two different data archives servers.

The EMBRACE Magnetometer Network is planned to cover most of the Easter Southern American longitudinal sector in 
order to fulfill a gap for magnetic measurement available online. The availability of fast internet, reliable energy supply and easy access were the key point for deciding the location of the first magnetometer stations of our network. Below, we present Table 1 with the location of the Embrace magnetometer stations, which started to be set in May 2011 and is originally planned to be concluded in December 2014. There also is additional information joined to this table that will be timely presented in this manuscript.

Each magnetic station is composed by the three-axis fluxgate magnetometer just described, a controller system and a personal computer for local data storage and internet FTP server. The sensor is buried 1-m deep, under a cover made of metal-free material to provide protection against moderate rain, winds and solar exposure. It is installed in a location 20 to $50 \mathrm{~m}$ apart of the main shelf where the controller system and the personal computer are located. The cable connecting the magnetic sensor to the controller system is sealed and buried 20-cm deep to avoid solar exposure and to provide at least a minimum of temperature protection. It uses military certified connectors to assure long durability. The room temperature of the main shelf is maintained under control.

\section{Procedure for calibrating the network equipments}

In order to assure the precision of the magnetic measurements performed with any network it is usual to calibrate all the individual equipment to either a reference fluxgate magnetometer or a high performance proton magnetometer, which can provide the absolute magnetic field. Since the goals of the Embrace Magnetometer Network are associated with measuring the variation of the magnetic field and its relative amplitude all over the South American instead of obtaining the absolute values of the magnetic field, we decided to adopt a reference fluxgate magnetometer to the network, which was set to be the one installed at CXP.

Thereafter, it is mandatory to submit all the magnetic equipments acquired to be part of the Embrace Magnetometer Network for a sensibility matching process within the reference magnetometer. This procedure consists of: (1) burying the sensor of the new magnetometer close (2-3 meter apart) to the sensor of the reference magnetometer with no changes to the factory settings; (2) letting it there to collect data for 3 months; (3) selecting the data collected during the 5 quietest days of each month from both magnetometers the reference and the new one; (4) averaging all the data to obtain the mean QDC for each magnetic component, which should be representative to the period of acquisition, avoid aliasing, outliers, and any other possible interference; (5) performing a correlation analysis based on a least squares linear fit of the QDC of reference versus the QDC under evaluation, for each magnetic component individually; (6) correcting the gain of the measurements of each individual magnetic component, based on the angular parameter derived from the estimated regression equation; (7) letting it there to collect data for another month; and (8) repeating the steps 3 to 6 from this procedure to ensure an angular parameter derived from the estimated regression equation between 0.98 and 1.02, i.e., a relative error lower than $2 \%$. An example of the graphs obtained during the individual magnetometers component calibration procedure is shown in Figure 1.
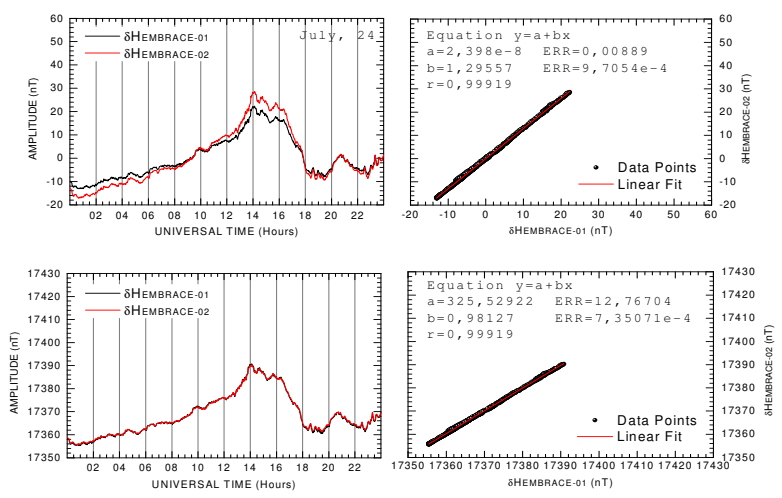

Figure 1. Diurnal variation of the $\mathrm{H}$ component measured on July 24, 2011 at CXP (left graphs) by the reference equipment (black line) and by the magnetometer under evaluation (red line), and scatter plots (black dots) of the reference QDC versus the QDC under evaluation for the same period of the first graph, with the estimated linear fit curve (red line), before (upper) and after (bottom left) the calibration procedures superimposed.

Table 1. Geographical location of the Embrace magnetometer stations with the corresponding magnetic latitude, dip angle, K9 threshold and designed code.

\begin{tabular}{|c|c|c|c|c|c|c|c|c|}
\hline \multirow{2}{*}{ Observatory } & \multirow{2}{*}{ IAGA Code } & \multirow{2}{*}{ Country } & \multicolumn{2}{|c|}{ Geographic } & \multirow{2}{*}{$\begin{array}{c}\text { Geomag. } \\
\text { Lat. }\left({ }^{\circ}\right)\end{array}$} & \multirow{2}{*}{ Altitude (m) } & \multirow{2}{*}{$\operatorname{DIP}\left({ }^{\circ}\right)$} & \multirow{2}{*}{$\begin{array}{c}\text { K9 } \\
\text { Thresholc }\end{array}$} \\
\hline & & & Lat. & Lon. & & & & \\
\hline Belém - PA & BLM & $\mathrm{BR}$ & $01^{\circ} 26^{\prime} 28^{\prime \prime S}$ & $48^{\circ} 26^{\prime} 40^{\prime \prime} \mathrm{W}$ & -00.4 & 016 & -00.80 & 600 \\
\hline São Luís - MA & SLZ & $\mathrm{BR}$ & $02^{\circ} 35^{\prime} 39 " \mathrm{~S}$ & $44^{\circ} 12^{\prime} 35^{\prime \prime} \mathrm{W}$ & -03.6 & 032 & -07.26 & 500 \\
\hline Cachimbo - PA & CXB & $\mathrm{BR}$ & $09^{\circ} 21^{\prime} 27^{\prime \prime S}$ & $54^{\circ} 54^{\prime} 53^{\prime \prime} \mathrm{W}$ & -04.0 & 464 & -07.99 & 500 \\
\hline Manaus - AM & MAN & $\mathrm{BR}$ & $02^{\circ} 54^{\prime} 52^{\prime \prime S}$ & $59^{\circ} 59^{\prime} 40^{\prime \prime} \mathrm{W}$ & -04.4 & 043 & 08.75 & 500 \\
\hline Boa Vista - RR & $\mathrm{BOA}$ & $\mathrm{BR}$ & $02^{\circ} 48^{\prime} 02^{\prime \prime} \mathrm{N}$ & $60^{\circ} 40^{\prime} 33^{\prime \prime} \mathrm{W}$ & -04.6 & 076 & -09.22 & 500 \\
\hline Eusébio - CE & EUS & $\mathrm{BR}$ & $03^{\circ} 52^{\prime} 48^{\prime \prime S}$ & $38^{\circ} 25^{\prime} 28^{\prime \prime} \mathrm{W}$ & -08.2 & 043 & -16.51 & 400 \\
\hline Palmas - TO & PAL & $\mathrm{BR}$ & $10^{\circ} 17^{\prime} 50^{\prime \prime S}$ & $48^{\circ} 21^{\prime} 41^{\prime \prime} \mathrm{W}$ & -08.3 & 231 & -16.52 & 400 \\
\hline Campo Grande - MS & CGR & $\mathrm{BR}$ & $20^{\circ} 30^{\prime} 24 " \mathrm{~S}$ & $54^{\circ} 37^{\prime} 04^{\prime \prime} \mathrm{W}$ & -13.7 & 540 & -26.29 & 350 \\
\hline Cachoeira Paulista - SP & CXP & $\mathrm{BR}$ & $22^{\circ} 42^{\prime} 07^{\prime \prime S}$ & $45^{\circ} 00^{\prime} 52^{\prime \prime} \mathrm{W}$ & -18.9 & 601 & -36.43 & 300 \\
\hline São José dos Campos - SP & SJC & $\mathrm{BR}$ & $23^{\circ} 12^{\prime} 31^{\prime \prime S}$ & $45^{\circ} 57^{\prime} 49^{\prime \prime} \mathrm{W}$ & -19.1 & 583 & -36.64 & 300 \\
\hline São Martinho da Serra - RS & SMS & $\mathrm{BR}$ & $29^{\circ} 26^{\prime} 36^{\prime \prime S}$ & $53^{\circ} 49^{\prime} 22^{\prime \prime} \mathrm{W}$ & -21.2 & 476 & -36.48 & 300 \\
\hline Rio Grande - TF & RGA & $A R$ & $53^{\circ} 47^{\prime} 09^{\prime \prime S}$ & $67^{\circ} 45^{\prime} 42^{\prime \prime} \mathrm{W}$ & -39.9 & 010 & -50.03 & 400 \\
\hline
\end{tabular}


On the left graphs of this figure we present the diurnal variation of the $\mathrm{H}$ component of the Earth's magnetic field measured on July 24, 2011 at CXP by the reference equipment (black line) and by the magnetometer under evaluation (red line), before (upper) and after (bottom) the calibration procedures. Similarly, we present the scatter plots (black dots) of the reference QDC versus the QDC under evaluation for the same period of the first graph, with the estimated linear fit curve (red line) superimposed on the right graphs. On the upper left corner of these two graphs one can found the estimated regression equation and its parameters.

\section{Procedure for obtaining the $\mathrm{K}$ scale and the corresponding scale for each magnetic station}

Currently, the Embrace Magnetometer Network is at its first stage of development. During this phase, we are not in condition to perform the complete magnetic analysis proposed by Bartels et al. (1939) and Mayaud (1968) since we have no enough data collected. Therefore, in order to have a proxy of a $\mathrm{K}$ scale for each magnetic station in our network we decided to use a mathematical approach. We looked at the available literature for the $\mathrm{K}$ scale established by several authors (e.g., Bartels et al., 1939; Jursa, 1995; Takahashi et al., 2001) for different magnetic observatories. The compilation of upper limits for three-hour-range indices $\mathrm{K}$ for different magnetic observatories is shown in Table 2 together with the observatories geographical location, magnetic latitude, dip angle, and the corresponding IAGA code.

From this information, we built a plot of the module of geomagnetic latitude of each observatory listed in the Table 2 versus the maximum value of range that classifies the disturbance registered at the particular observatory as $\mathrm{K} 9$. Thereafter, we performed a least squares polynomial fit to get a mathematical relationship between these two variables. Figure 2 shows the plot of the maximum range for achieving $\mathrm{K} 9$ value, per geomagnetic latitude of the observatories (black dots) from which we were able to find the $\mathrm{K}$ range scales. In addition, we plot the polynomial fit superimposed to it and plot the geomagnetic latitude of the magnetic stations of the Embrace Magnetometer Network (blue dots).

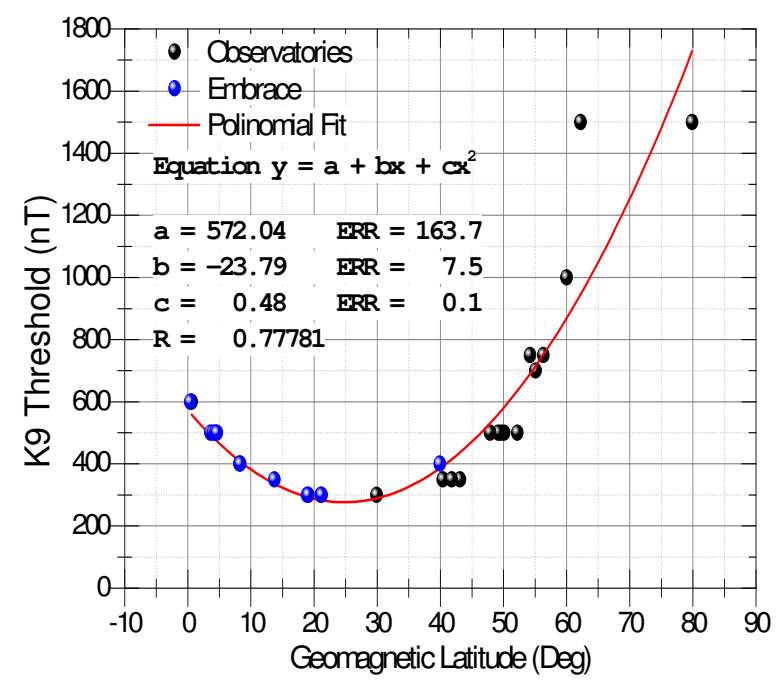

Figure 2. Geomagnetic latitude of the observatories (black dots) and Embrace stations (blue dots) versus its maximum range corresponding to a classification $\mathrm{K} 9$, and the polynomial fitting (red curve).

This simple method resulted in the equation below and allowed us to obtain the $\mathrm{K} 9$ threshold for all the magnetic stations of the Embrace Magnetometer Network entering their geomagnetic latitude in the above equation, which are shown in the last column of the Table 1.

$$
\text { K9 }=0.48(\text { GeomLat }) 2-23.79(\text { GeomLat })+572.04
$$

Afterwards, we derive the complete scale of the $\mathrm{K}$ index for all the magnetic station by keeping the proportionality with the observatories scales. Thereafter, we have started obtaining the mean QDC for each magnetic component measure at each

Table 2. Geographical location of different magnetic observatories with the corresponding magnetic latitude, dip angle, K9 threshold and the IAGA code.

\begin{tabular}{|c|c|c|c|c|c|c|c|c|}
\hline \multirow{2}{*}{ Observatory } & \multirow{2}{*}{ IAGA Code } & \multirow{2}{*}{ Country } & \multicolumn{2}{|c|}{ Geographic } & \multirow{2}{*}{$\begin{array}{c}\text { Geomag. } \\
\text { Lat. }\left({ }^{\circ}\right)\end{array}$} & \multirow{2}{*}{ Altitude $(\mathrm{m})$} & \multirow{2}{*}{$\operatorname{DIP}\left({ }^{\circ}\right)$} & \multirow{2}{*}{$\begin{array}{c}\text { K9 } \\
\text { Threshold }\end{array}$} \\
\hline & & & Lat. $\left({ }^{\circ}\right)$ & Lon. $\left({ }^{\circ}\right)$ & & & & \\
\hline Huancayo & HUA & $\mathrm{PE}$ & -12.05 & 284.66 & -0.6 & 3313.0 & -02.10 & 600 \\
\hline Honolulu & HON & US & 21.32 & 201.94 & 21.1 & 4.0 & 39.14 & 300 \\
\hline San Juan & SJG & $\mathrm{RQ}$ & 18.38 & 293.88 & 29.9 & 424.0 & 52.60 & 300 \\
\hline Tucson & TUC & US & 32.25 & 249.17 & 40.4 & 946.0 & 59.84 & 350 \\
\hline Watheroo & WAT & AS & -30.32 & 115.88 & -41.8 & 200 & -64.49 & 350 \\
\hline Fresno & FRN & US & 37.09 & 240.28 & 43.1 & 331.0 & 61.73 & 350 \\
\hline Hartland & HAD & UK & 51.00 & 355.52 & 47.9 & 95.0 & 66.32 & 500 \\
\hline Boulder & $\mathrm{BOU}$ & US & 40.14 & 254.76 & 49.2 & 1682.0 & 67.45 & 500 \\
\hline Fredericksburg & FRD & US & 38.21 & 282.63 & 49.6 & 69.0 & 68.28 & 500 \\
\hline Cheltenham & $\mathrm{CLH}$ & US & 38.73 & 283.16 & 50.1 & 70.0 & 71.49 & 500 \\
\hline Niemegk & NGK & GE & 52.07 & 12.68 & 52.2 & 78.0 & 67.25 & 500 \\
\hline Saint Johns & STJ & CA & 47.59 & 307.32 & 54.2 & 100.0 & 68.60 & 750 \\
\hline Newport & NEW & US & 48.26 & 242.88 & 55.1 & 770.0 & 71.49 & 700 \\
\hline Ottawa & OTT & CA & 45.40 & 284.45 & 56.3 & 75.0 & 72.19 & 750 \\
\hline Sitka & SIT & US & 57.05 & 224.67 & 60.0 & 24.0 & 74.57 & 1000 \\
\hline Meanook & MEA & CA & 54.62 & 246.67 & 62.2 & 700.0 & 76.96 & 1500 \\
\hline Godhavn & $\mathrm{GDH}$ & $\mathrm{GL}$ & 69.24 & 306.48 & 79.9 & 69.0 & 81.77 & 1500 \\
\hline
\end{tabular}


Embrace stations in order to get the component deviation relative to a quiet behavior. This task is not finished so far and some particularities regarding the QDC deviation are addressed ahead. However, ignoring the difference with respect to the QDC and considering the absolute variation only, we present Figure 3 with samples of the time evolution of what we convention to call the pseudo-K index registered at some stations. In this figure, we also present the time evolution of the $\mathrm{H}$ component of the Earth's magnetic field in the top graph. Measurements registered at SLZ are presented with the red line, at EUS with the green line, and at CXP with the blue line. The colors of the bars in the graph represent the level of disturbances with respect to the $\mathrm{K}$ index at that particular station, being green to $K$ lower than or equal 4 , blue for $\mathrm{K}$ equal to 5 , and red for $\mathrm{K}$ equal or higher than 6 .

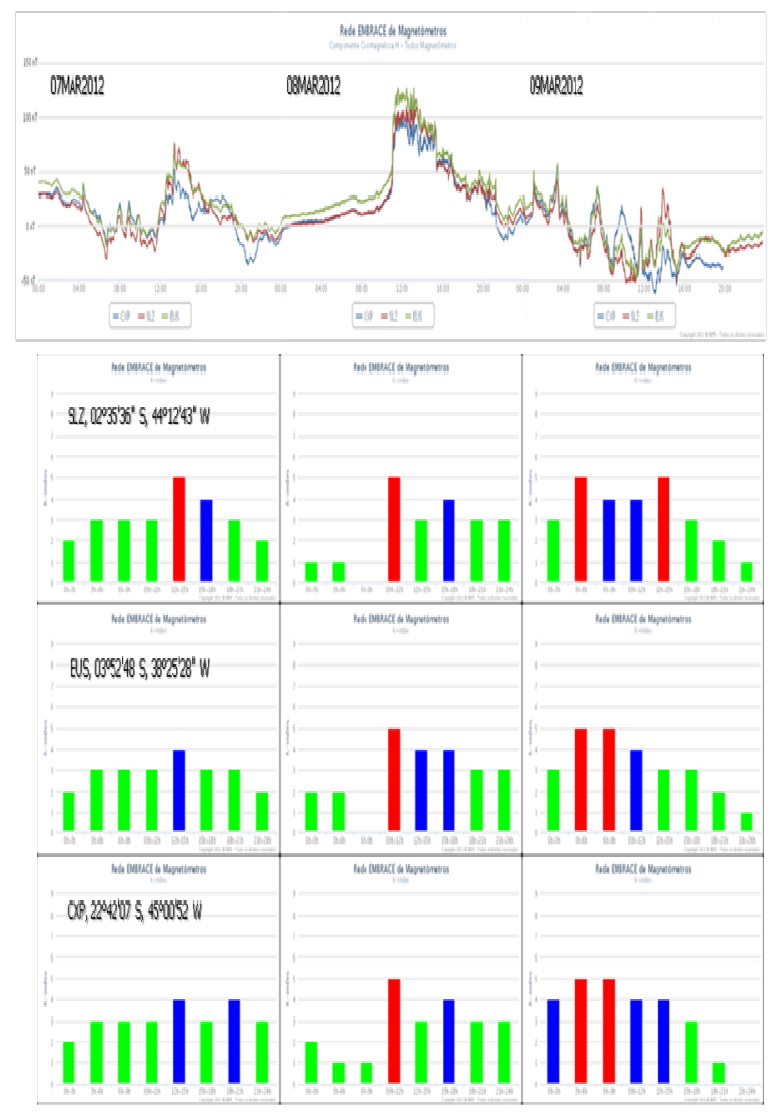

Figure 3. Time evolution of the (top graph) $\mathrm{H}$ component of the Earth's magnetic field and the (bar graph) pseudo-K index registered at (top bars, red line) SLZ, (middle bars, green line) EUS and (bottom bars, blue line) CXP stations during the disturbed period 07 to 09 March 2012.

In Figure 3, we called the graph bar as the pseudo-K index because we only took into consideration the variation of the $\mathrm{H}$ component to derive it. As we said, we did not subtract the mean QDC from the diurnal variation of the magnetic components. Since these two steps are mandatory to have a real $\mathrm{K}$ index we prefer to call it pseudo-K index. Therefore, the purpose of this figure is to show the performance of the network stations that are already operational (continuously sending data every 5 minutes to our data server) and to check the response of the network under magnetic disturbances like that registered in 2012.

From the simple test, we are able to see that the available stations presented a coherent response to the presence of the magnetic disturbance. All the stations recorded the $\mathrm{H}$ component variation in the same way and at the same time. If we take a look at for example, the abrupt variation registered at 11 UT on March 08. The jump in the graph is simultaneously registered with very similar amplitudes at the three available stations. It is confirmed by the pseudo- $K$ index in bars graph the below. Despite good correlation among all the $\mathrm{H}$ component excursions along the days, some differences in the pseudo-K index can be observed. This may be due to values of the range close to the transition between the indices steps, which reinforcing the need for referring the $H$ variation to the QDC and for using the appropriated K9 values for each station.

\section{Particularities regarding the QDC deviation}

We are currently working on the determination of the QDC for all the magnetic stations of the Embrace Magnetometer Network. However, this task - usually thought to be simple - is quite complicated in the Brazilian sector. Due to large magnetic declination, reaching -20 degrees at low latitudes, the QDC can drastically change with the year once the main magnetic field, subject to the secular variation, is drifting westward. See, for instance, the example difference between the QDC obtained at the SLZ in 2002 and 2012 in the Figure 4.
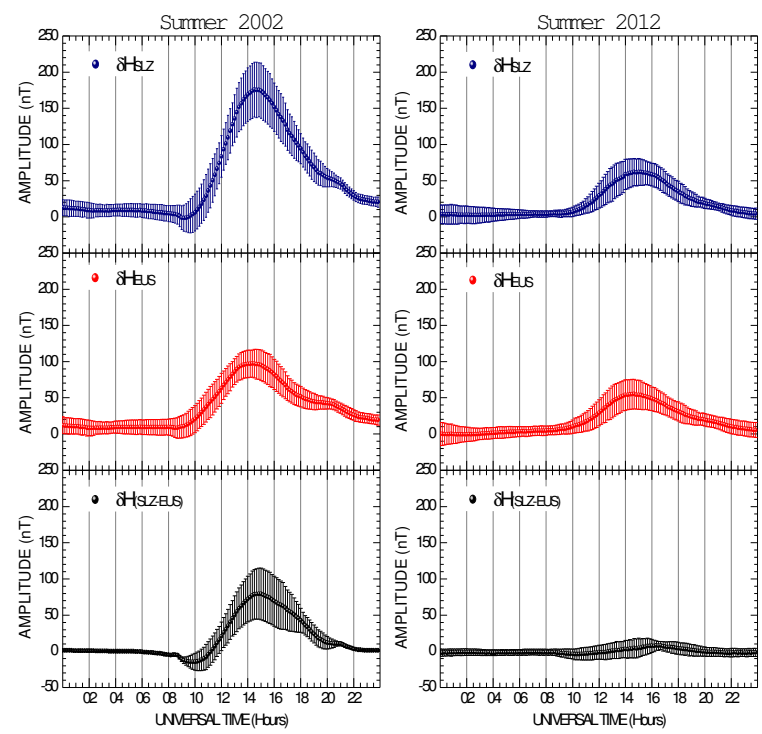

Figure 4. Time evolution of the $\delta \mathrm{H}$ component of the Earth's magnetic field registered at the SLZ station (blue line), the EUS station (red line), and the difference between them form the summer of 2002 (left graphs) and summer of 2012 (right graphs).

Observing this figure we clearly see that the measurement made at the SLZ station registered the strong influence of the EEJ in 2002, evidenced by the strong variations seen in the lower graph. We also see that such clear influence is shot down in 2012. There is also the problem of the seasonal variation of the Solar Quiet (Sq) current system that certainly influences the magnetic records at the ground level. But this subject is not addressed in the present work. 


\section{Final Remarks}

We have presented some results obtained from the first steps regarding the development of the South American K index based on the magnetic measurement made by the Embrace Magnetometer Network. After briefly describing the magnetometer used to monitor the magnetic field, we described the network and the procedure used to calibrate all the network equipments, including an example of errors from non calibrated equipments. We also introduced the step-bystep the procedure to obtain the $\mathrm{K}$ scale and the corresponding scale for each magnetic station and provided the equation to perform that. Finally, we provided examples of the pseudo-K index variation registered at the SLZ, EUS and CXP stations, and discussed about some particularities regarding the quiet day curve deviation, spatially with respect to the long term variation.

\section{Acknowledgments}

C. M. Denardini thanks to CNPq/MCTI (Grant 305242/2011-3), to FAPESP (Grant 2012/08445-9), and to the Brazilian Government (Program 2056, Budget Action N387, Budget Plan 08/2013-2017), which supported both the scientific and infrastructure projects that gave birth to the Embrace Magnetometer Network. M. Rockenbach thanks to CNPq/MCTI (Grant 300300/2012-3) and to FAPESP (Grant 2011/11581-9).

\section{References}

Bartels, J., N. H. Heck, and H. F. Johnston, The three-hour-range index measuring geomagnetic activity, Terr. Magn. Atmos. Electr., 44(4), 411-454, 1939.

Chapman, S., Bartels, J. Geomagnetism. London: Oxford University Press, 1940. v. 2.

Jursa, A, Handbook of Geophysics and the Space Environment, published by US Air Force Geophysics Laboratory, 1985.

Lindzen, R. S., Chapman, S. Atmospheric tides. Space Science Review, v. 10, n. 3, 1969.

Maeda, K., Kato, S. Electrodynamics of the ionosphere. Space Science Review, v. 5, n. 57, 1966.

Matsushita, S. Dynamo currents, winds and electric fields. Radio Science, v. 4, n. 9, p. 771, 1969.

Mayaud, P. N., Indices Kn, Ks, et Km, pp. 1-155, Éditions du Centre National de la Recherche Scientifique, Paris, 1968.

Mayaud, P. N., Equatorial counter-electrojet - a review of its geomagnetic aspects, Journal of Atmospheric and Terrestrial Physics, 39 (9-10), 1055-1070, 1977.

Maynard N. C., Cahill Jr., L. J. Measurements of the equatorial electrojet over India. Journal of Geophysical Research, v. 70, n. A23, p. 5923-5936, 1965a.

Maynard N. C., Cahill Jr., L. J. Preliminary results of the measurements of Sq currents and equatorial electrojet near Peru. Journal of Geophysical Research, v. 70, n. A23, p. 5975-5978, 1965b.

Moro, J., C.M. Denardini, E. Correia, E. ; M.A. Abdu, N. J. Schuch, and K. Makita. Correlation between the cosmic noise absorption calculated from the SARINET data and the energetic particles measured by MEPED: Simultaneous observations over SAMA region. Advances in Space Research, v. 51, p. 1692-1700, 2012.

Rostoker, G., Geomagnetic Indexes, Reviews of Geophysics and Space Physics, 10 (4), 935-951, 1972.

Sugiura, M., Cain, J. C., A model equatorial electrojet. Journal of Geophysical Research, v. 71, n. A7, p. 1869-1877, Apr. 1966.
Takahashi, K., B. A. Toth, and J. V. Olson, An automated procedure for near-real-time Kp estimates, J. Geophys. Res., 106(A10), 210172,032, 2001.

Vestine, E. H. The upper atmosphere and geomagnetism. In: Ratcliffe, J. A. ed., Physics of the Upper Atmosphere, New York, 1960. Cap. 10. 